\title{
Interactive comment on "Surface waters properties in the Laptev and the East-Siberian Seas in summer 2018 from in situ and satellite data" by Anastasiia Tarasenko et al.
}

\section{Anastasiia Tarasenko et al.}

tad.ocean@gmail.com

Received and published: 15 May 2020

\section{General comments:}

1. The authors define the plume as water mass with salinity less than 30 (e.g., page 10, line 28). However, the majority of works that deal with river plumes in different World coastal areas define river plumes as relatively shallow surface-advected water masses bounded with large salinity gradient at their border with ambient sea. Existence of this salinity gradient determines significantly different dynamics of river plumes (governed by buoyancy force), as compared to ambient sea, which is the main reason to distinguish river plumes as individual water masses. River plumes formed at the shelf of the 
Laptev and East-Siberian seas generally have sharp salinity gradients at isohalines of 15-25, while water masses with greater salinity are regarded as ambient shelf water. Thus, I recommend the authors to determine salinity border of the Lena plume based on maximal salinity gradient and to distinguish wind- driven dynamics and variability of river plumes and more "typical ocean dynamics" of shelf water mass.

Interactive

Answer:

When we discuss the river waters (and the "river plume"), we mean some water mass with a river-origin, already transformed to some mix of river and sea waters (not taking into account precipitation and brine from sea ice formation and melting now, as their substantially smaller contribution cannot be estimated with current satellite data). As in other studies that mean that the definition of "river plume" or "river water" becomes arbitrary, depending on the authors of study and the region of interest. Before writing this paper, we regarded the gradients of salinity as well, and found that the highest values of salinity gradients roughly correspond to the position of 29 isohaline. In Fig. 1 , there are high gradients of salinity at 15, 20, 25, and 29 isohalines. Knowing that the freshwater input in this area comes mainly from the rivers, as we demonstrate it later with the oxygen isotope analysis (please, see a new version of manuscript), we have just chosen the furthest position of "river water presence" as a virtual "river plume".

2. In this study you use SSS data from SMOS satellite which spatial resolution is $50 \mathrm{~km}$ (page 5, line 18). However, you deal with salinity maps with $15 \mathrm{~km}$ spatial resolution (page 5, line 18). Did you reduce spatial resolution only by reprojection?

\section{Answer:}

The "initial" SMOS instrument resolution is $50 \mathrm{~km}$ (which we meant to explain in 2.2.2, line 17-18), but the SMOS SSS product distributed by ESA is already oversampled in the ISEA grid with a resolution of $15 \mathrm{~km}$. In other words, the spatial resolution of SMOS SSS Level 2 v662 product is $15 \mathrm{~km}$, we just resampled all satellite products at the same grid for convenience. This "oversampling" of SMOS SSS at $15 \mathrm{~km}$ is practical

OSD 
for two reasons. First, to conserve the real salinity gradients observed with in situ measurements and not smooth them to $50 \mathrm{~km}$ for the further comparison with SMOS SSS. The spatial resolution of ship measurements depends on the ship speed (8 knots $\sim 3 \mathrm{~m} / \mathrm{s})$, pumping speed $(16 \mathrm{l} / \mathrm{s})$ and the CTD measurement frequency $(24 \mathrm{~Hz})$, and is of order $\mathrm{O}(1) \mathrm{m}$. After processing the raw data, its resolution is $\mathrm{O}(250) \mathrm{m}$. A 7.5-km in situ measurement average corresponds to 30 minutes of TSG measurement, as we mention at line 6, p.3.1.1 (and 15-km pixel represents one hour of measurements). Second, to put SSS on the same grid as rather high-resolution SST for the further calculations, e.g., density.

3. In this study you deal with in situ thermohaline data obtained from the depth of 6.5 $\mathrm{m}$ (page 7 , line 3 ). However, salinity at this depth can be significantly different from surface salinity (even more than several units) especially within the river plumes. Thus, your usage of this data to compare and validate satellite data requires additional proof, e.g., based on vertical thermohaline measurements.

Answer: To investigate if the TSG measurements can be used to study the surface layer in a highly stratified Laptev sea, we calculated a summer mixed layer depth following de Boyer Montégut et al. (2004) method based on density and temperature gradient thresholds (Fig.2, 3: Colored profiles show the cases when the MLD is below $7 \mathrm{~m}$ depth and gray profiles indicate when the MLD is above $7 \mathrm{~m}$ depth). The MLD is found at a depth of the first maximum temperature gradient below a depth of defined (by given threshold) density gradient (see de Boyer Montégut et al. (2004) for details). Using the same logic, we computed MLD also with density and salinity vertical profiles. The threshold chosen for practical density gradient was 0.3 , and 0.2 units for conservative temperature and practical salinity gradients. Regarding the MLD calculated from salinity (MLDsal), most of the measured vertical profiles had the MLDsal below $7 \mathrm{~m}$ depth $75.17 \%$. The median value of MLDsal was $11.99 \mathrm{~m}$. As for the temperature (MLDtemp), $81.37 \%$ of profiles had the MLD below $7 \mathrm{~m}$ depth, with a median value of MLDtemp $=13.50 \mathrm{~m}$. Thus, we conclude that in most of the cases the upper $12 \mathrm{~m}$

OSD

Interactive comment
Printer-friendly version

Discussion paper 
of the surface layer was homogeneous, and our CTD and TSG measurements can be used for the validation of satellite data.

OSD

4. The results of validation of satellite SSS and in situ salinity obtained from the depth of $6.5 \mathrm{~m}$ does not seem convincing, especially at the areas influenced by freshwater discharge (Section 3.1.2 and Figure 3). We see underestimation of salinity by several units for almost all measurements. I recommend authors to deal with salinity gradients rather than absolute salinity values, e.g., to show that satellite SSS data reproduces well and shows relative salinity differences if it really does.

Answer: Indeed, both SST and SSS compared to in situ measurements have some biases. Nevertheless, we consider that the bias (or "mean of difference" between SSS and in situ data) is close to be linear, so we extract it from the initial dataset. This study was a case study for a particular period of time and a particular region, and one of the important milestones of this work was a prototype of the "Arctic SSS" product created for it. The quality of this SSS product was the best for the Arctic at the moment of writing the manuscript (we compared it with others, such as other SMOS or SMAP SSS, but didn't present). Later on, we created a first version of SMOS SSS for the whole Arctic (Supply Alexandre, Boutin Jacqueline, Vergely Jean-Luc, Kolodziejczyk Nicolas, Reverdin Gilles, Reul Nicolas, Tarasenko Anastasiia (2020). SMOS ARCTIC SSS L3 V1.0 maps produced by CATDS CEC LOCEAN. SEANOE. https://doi.org/10.17882/71909. It can be check it here: https://www.seanoe.org/data/00607/71909/ ). To convince that the resulting SSS (before additional filtering of MIZ areas) resembles the measurements of TSG, we propose another graphical form of comparison: the timeseries of SSS and TSG-measured salinity in Fig. 4. The largest difference between SSS and in situ salinity is observed when the ship was working in MIZ areas (beginning of September and September 13-17). These "ice" pixels were filtered afterwards.

As for the high error at $74^{\circ} \mathrm{N} 136^{\circ} \mathrm{E}$, we suppose, it is the effect of the Stolbovoy Island present there. In the section with SSS description we mention that the closeness
Interactive comment
Printer-friendly version

Discussion paper 
to the coastline deteriorates the quality of SSS estimates. To avoid the "coastline" contamination we applied a $25-\mathrm{km}$ mask around all islands and coasts.

OSD

5. Ranges of temperature and salinity values used to determine different water masses at the study area are heuristic and are not based on any precise idea (Section 5 and Table 1). What is the reason to select $T=3^{\circ} \mathrm{C}$ and $S=25$ and 29 as borders between water masses? Why you determine 6 water masses? Why not to determine 5 or 7 ?

Answer: This section is based on the same principles as a classic T-S analysis, with the main difference that the amount of available points when use SST-SSS diagram is several orders higher than from classical CTD measurements. Identifying the core of each water mass stays heuristic in both cases. A chosen number of water masses corresponds to the number of "water mass cores", defined by the density of points on the SST-SSS diagram.

6. Reconstructed circulation in the Laptev and East-Siberian sea based on Ekman theory does not seem convincing, especially the presented patchy distribution of upwelling and downwelling areas (Section 4.1.2 and Figure 9e). These results have to be supported by in situ measurements and/or numerical modelling. Answer: The Ekman transport was recalculated for the updated version of manuscript using the recommendations of all reviews (Fig. 5, 6). Numerical modeling is out of scope of this study.

7. Propagation of freshened water from the Kara Sea and its presumed missing with Lena plume in the Olenekskiy bay requires additional proof by in situ measurements and/or numerical modelling (page 19, lines 6-9). The role of the Khatanga plume in this process (as well as the plume of the Olenyok River surprisingly not mentioned here) also should be supported by additional data. Answer: Unfortunately, no in situ measurements were carried out in the coastal area during the period of our study neither by the expedition Arktika-2018, nor by any other expedition to the best of our knowledge. The results of numerical modeling should be validated separately, so we consider satellite data the only available source of information. The Kara-origin of the
Interactive comment
Printer-friendly version

Discussion paper 
freshwater appearing in the Vilkitskiy Strait and northward is well-seen on the time series of SSS fields. A special role of the Khatanga, the Anabar, the Olenyok, and the Yana Rivers should be studied additionally. It was not discussed in this paper, because we had neither the appropriate information on their discharge, nor in situ/satellite measurements in the close vicinity of their estuaries/deltas.

Interactive

comment

Interactive comment on Ocean Sci. Discuss., https://doi.org/10.5194/os-2019-60, 2019. 
OSD

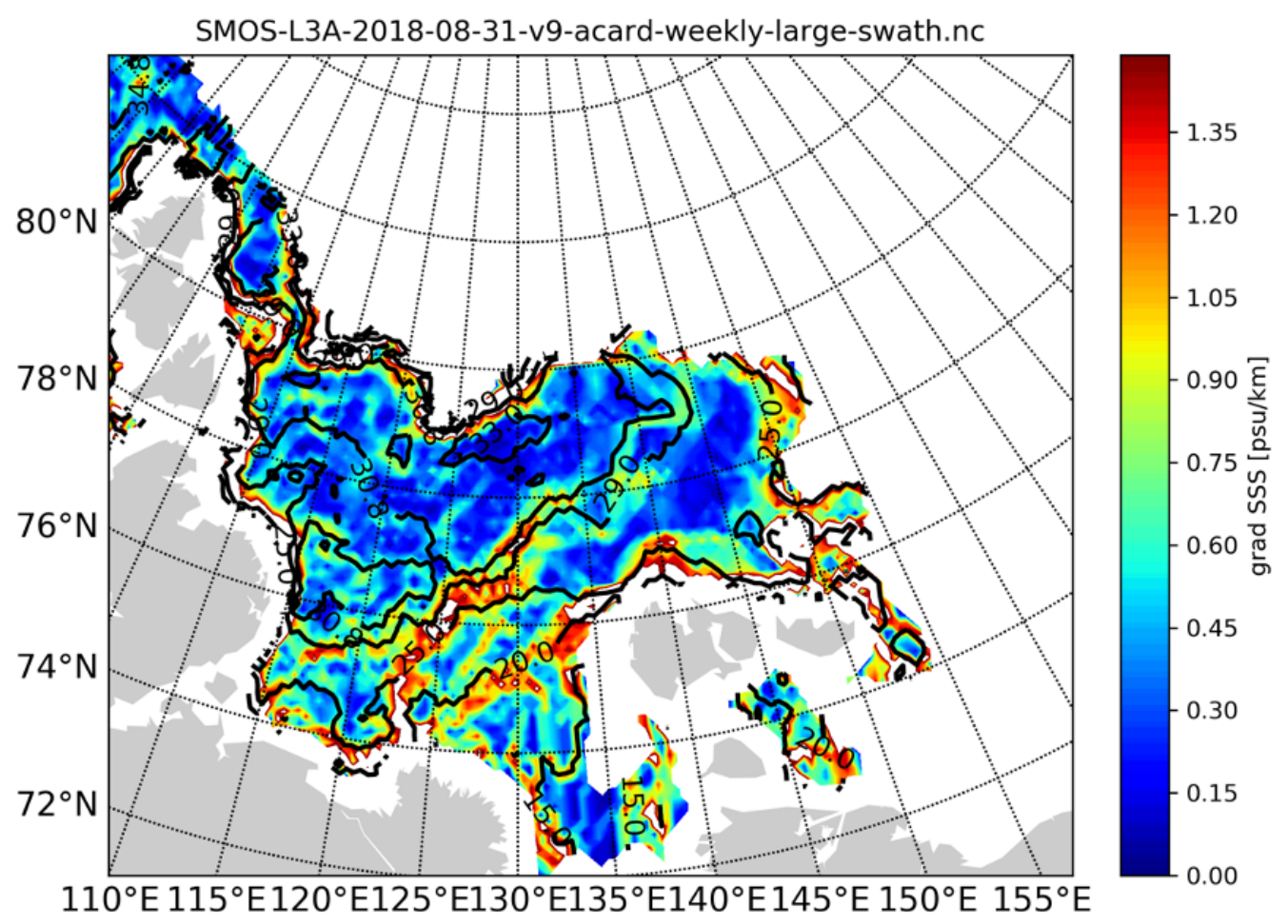

Interactive

comment

Fig. 1. Gradient of salinity for August 31, 2018 calculated from SSS SMOS "A" (see the de- 
OSD

Upper layer temperature, CTD from ARKTIKA-2018

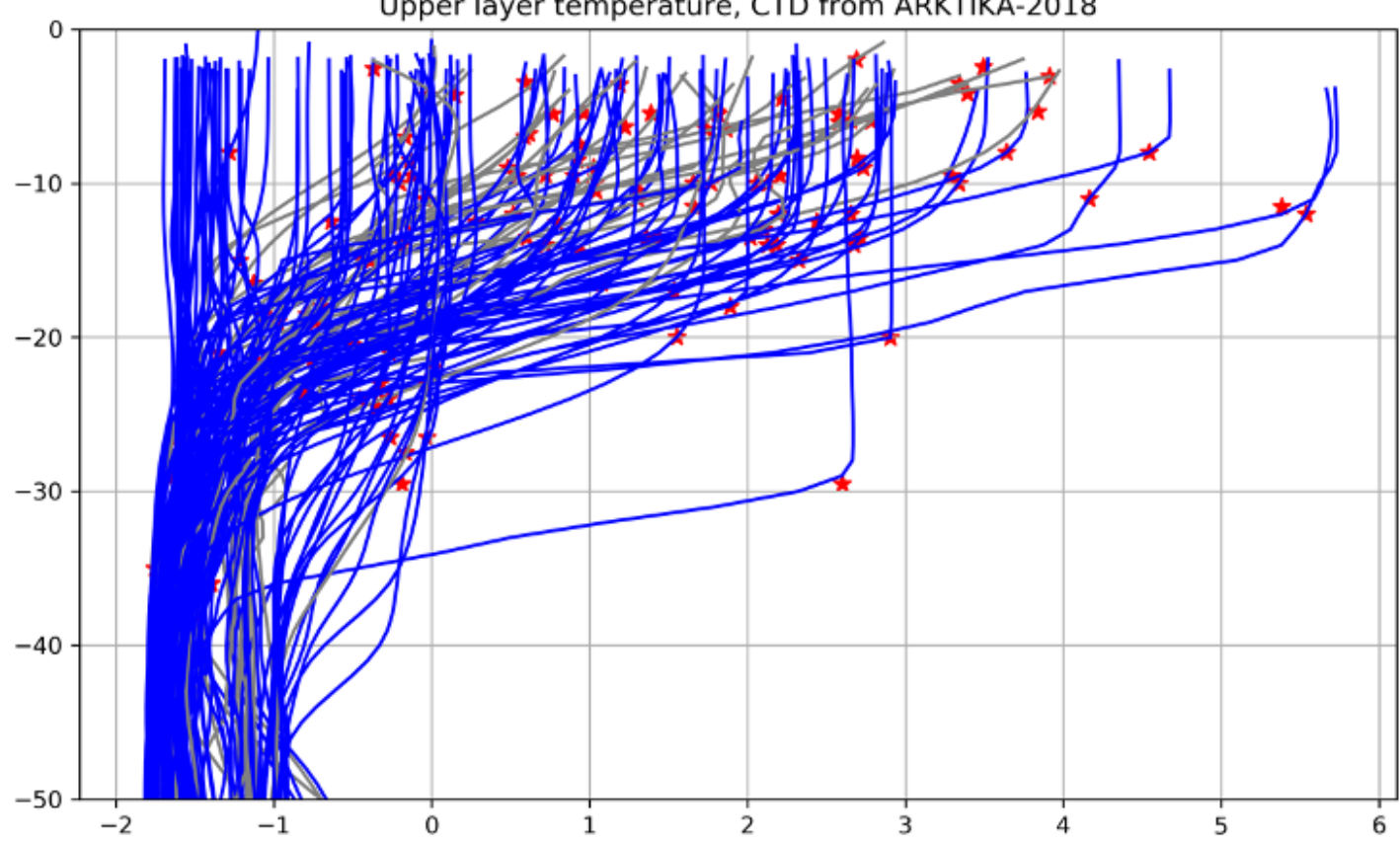

Interactive

comment

Fig. 2. Vertical profiles of conservative temperature from CTD measurements in the upper 50 meters. Red stars indicate the mixed layer depth, calculated using de Boyer Montégut et al. (2004) method 
OSD

Upper layer salinity, CTD from ARKTIKA-2018

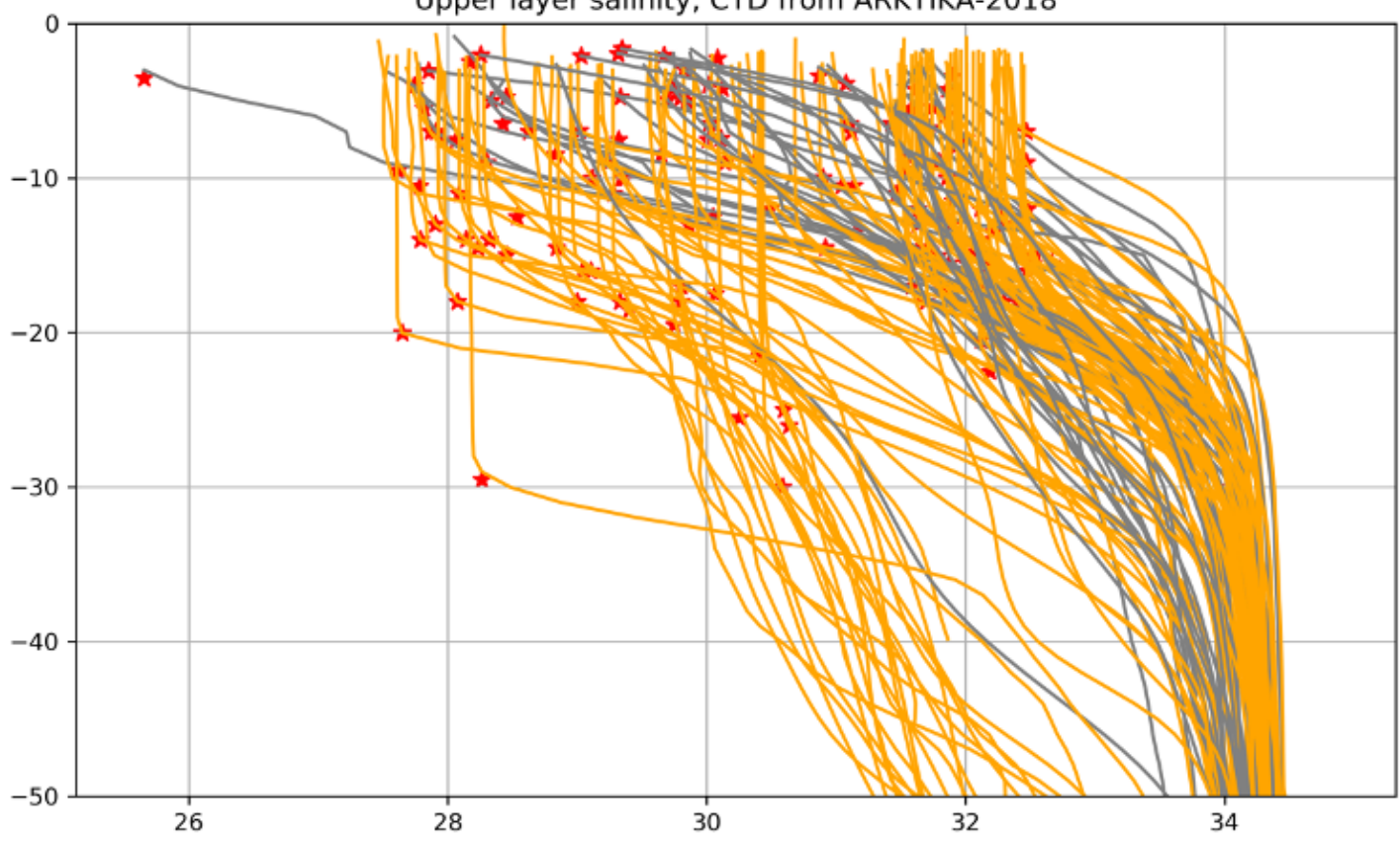

Interactive

comment

Fig. 3. Vertical profiles of practical salinity (b) from CTD measurements in the upper 50 meters. Red stars indicate the mixed layer depth, calculated using de Boyer Montégut et al. (2004) method 


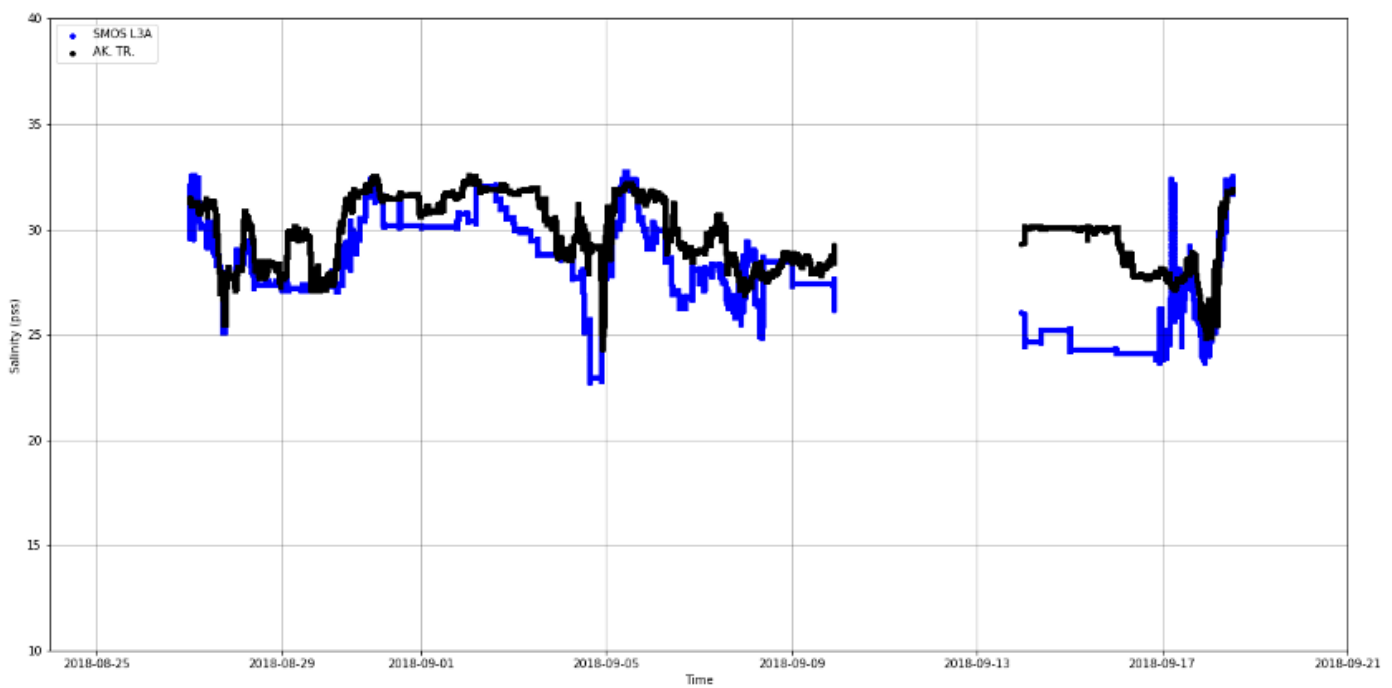

Interactive comment

Fig. 4. The time series of TSG-measured salinity (black line) and collocated SMOS SSS measurements. 
OSD

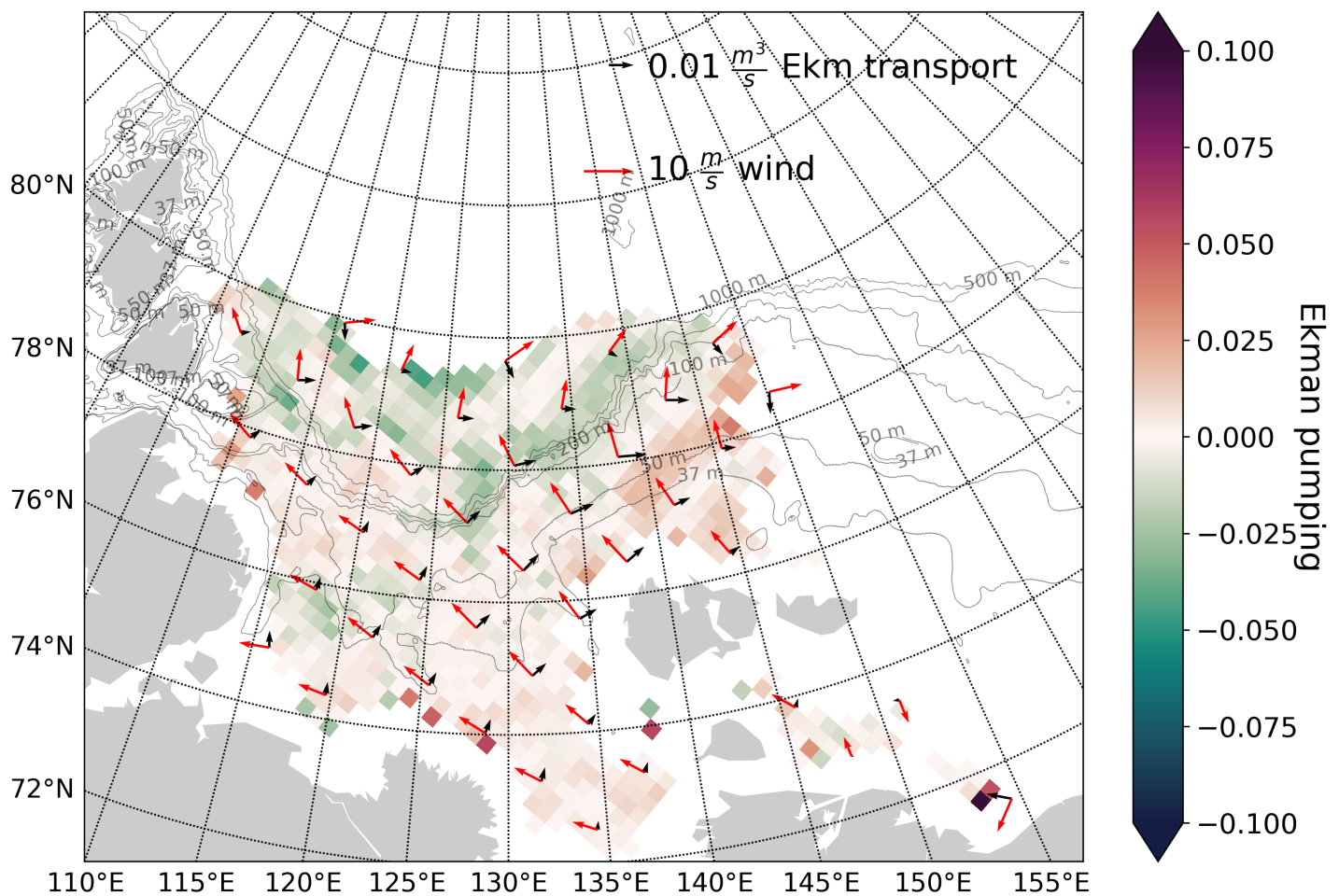

\section{Interactive comment}

Fig. 5. Ekman pumping (in color) and horizontal transport for August 2018 calculated from satellite data 
OSD

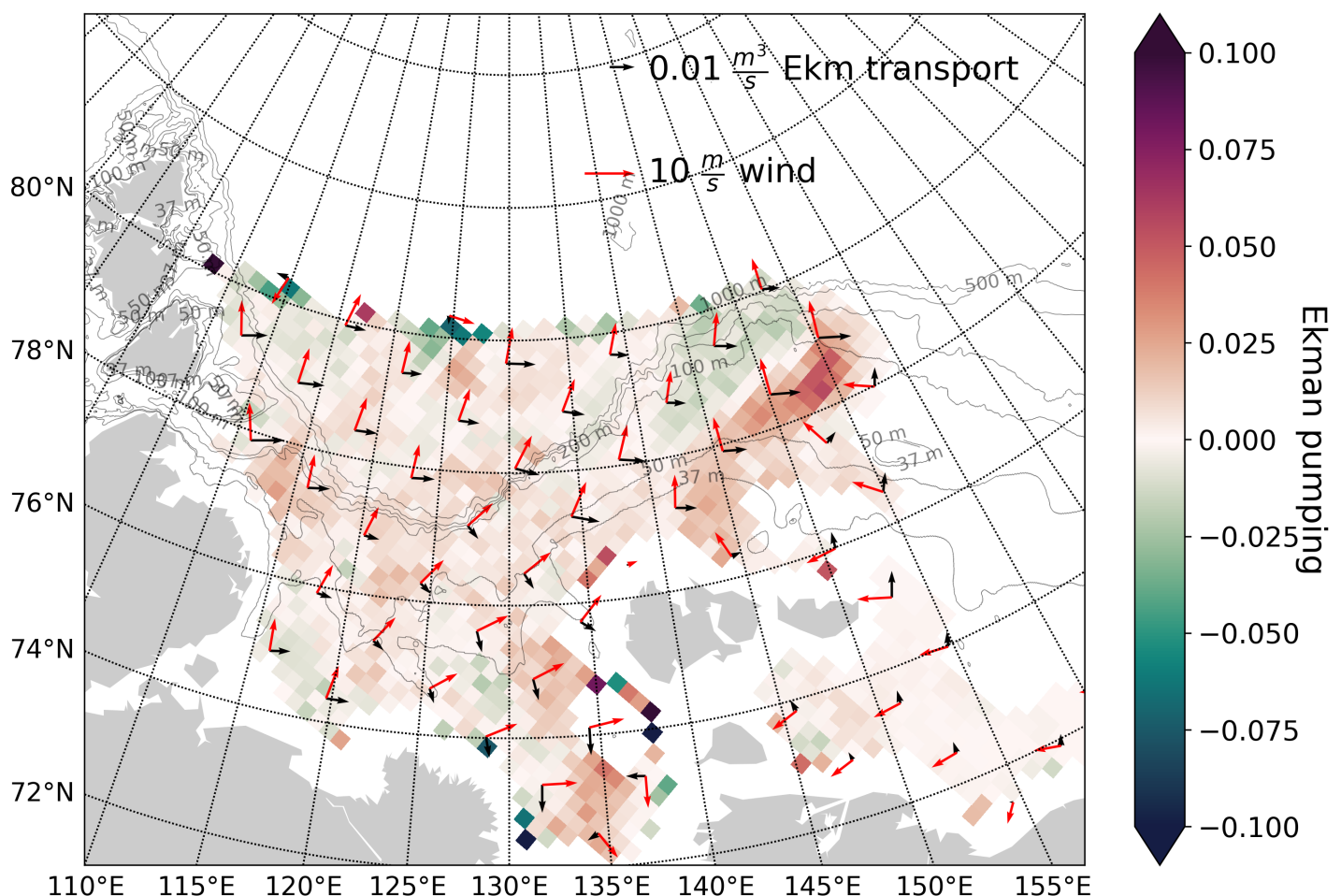

\section{Interactive comment}

Fig. 6. Ekman pumping (in color) and horizontal transport for September 2018 calculated from satellite data 